\title{
ZS Research Square

\section{Traumatic globe rupture after non-Descemet's stripping automated endothelial keratoplasty with scleral suture fixation of intraocular lens: a case report}

\author{
Akitomo Narimatsu ( $\square$ a.narimatsu1128@gmail.com ) \\ Tokyo Medical University https://orcid.org/0000-0002-0073-3162 \\ Takaaki Hattori \\ Tokyo Medical University \\ Haruki Katahira \\ Tokyo Medical University \\ Teruumi Minezaki \\ Tokyo Medical University \\ Shigeto Kumakura \\ Tokyo Medical University \\ Hiroshi Goto \\ Tokyo Medical University
}

\section{Case Report}

Keywords: Descemet's stripping automated endothelial keratoplasty, traumatic globe rupture, corneal transplantation

Posted Date: January 3rd, 2019

DOI: https://doi.org/10.21203/rs.2.162/v1

License: (c) (i) This work is licensed under a Creative Commons Attribution 4.0 International License. Read Full License 


\section{Abstract}

Background: To report the first case of traumatic globe rupture after non-Descemet stripping automated endothelial keratoplasty (nDSAEK) with scleral suture fixation of intraocular lens (IOL).

Case presentation: A 71-year old male was referred to our hospital with reduced vision in his left eye. He underwent cataract surgery in his left eye about 10 years ago. At presentation, slit-lamp examination of his left eye showed aphakic bullous keratopathy. We performed nDSAEK with scleral suture fixation of IOL. The surgical outcome was favorable. At 5 years after nDSAEK, he sustained globe rupture in his left eye from a fall. Slit-lamp examination demonstrated wound dehiscence and iris prolapse beneath the conjunctiva. However, the transplanted endothelium and Descemet's membrane was attached completely to the recipient cornea, and there was no dislocation of the implanted IOL. No abnormal findings were observed in the posterior segment. We performed wound suturing and iris reconstruction. After 45 months, recipient and donor cornea retained clarity, and his visual acuity was 20/25.

Conclusions: We encountered a patient with traumatic globe rupture after nDSAEK. It can be presumed that traumatic wound dehiscence after DSAEK is better visual outcome than traumatic wound dehiscence after conventional PKP. DSAEK might be resistant to traumatic injury because of the minimal incision than PKP.

Key words: Descemet's stripping automated endothelial keratoplasty, traumatic globe rupture, corneal transplantation

\section{Background}

Traumatic globe rupture after keratoplasty occurs at $n$ incidence of 0.6 to $5.8 \%[1,2]$. Several clinical studies have reported globe rupture after penetrating keratoplasty (PKP) and deep anterior lamellar keratoplasty (DALK) [3-7]. Kawashima et al. [1] reported that the incidence of traumatic wound dehiscence after PKP was 2.0囚 and that after DALK was 0.5区.

Descemet's stripping automated endothelial keratoplasty (DSAEK) is a well known surgical procedure for the treatment of endothelial dysfunction $[8,9]$. The advantages of DSAEK include the small incision and the reduction of postoperative astigmatism. These advantages of DSAEK lead to more rapid visual recovery compared with PKP. In Japan, Fuchs endothelial dystrophy is a less frequent cause of corneal endothelial dysfunction compared with cataract surgery and argon laser iridotomy. Therefore, nonDescemet stripping automated endothelial keratoplasty (nDSAEK) is appropriate and has been widely used for the treatment of bullous keratopathy. On the other hand, although traumatic injury after DSAEK may occur at similar frequency as other keratoplasty modalities, only few studies have reported postoperative trauma related to DSAEK. In particular, there is no previous report on traumatic wound dehiscence after DSAEK.

We report a case of traumatic wound dehiscence five years after nDSAEK, with good clinical outcome. 


\section{Case Presentation}

A 71-year old male was referred to our hospital with reduced vision in his left eye. He underwent cataract surgery in his left eye about 10 years ago. At presentation, slit-lamp examination of his left eye showed aphakic bullous keratopathy, and visual acuity was $10 / 200$. We performed nDSAEK with scleral suture fixation of intraocular lens (IOL) (the first operation). The first operative procedures were performed as reported previously [1, 2]. The donor tissue was cut with a punch $8 \mathrm{~mm}$ in diameter. The width of the wound was $7.5 \mathrm{~mm}$ at 11 o'clock position. Then we performed scleral suture fixation of a $7-\mathrm{mm}$ threepiece polymethyl methacrylate IOL. Finally, we inserted the donor graft and injected air into the anterior chamber. After surgery, the donor graft attached well and bullous keratopathy was ameliorated. His visual acuity improved to 20/25 and endothelial cell count was 1513 cells $/ \mathrm{mm}^{2}$ (Fig. 1).

At 5 years after the first operation, he had a fall and sustained globe rupture in his left eye. When he visited our hospital immediately, his visual acuity was $4 / 20$ and intraocular pressure (IOP) was $0 \mathrm{mmHg}$. Slit-lamp examination demonstrated dehiscence of the wound from the first operation and prolapse of the iris beneath the conjunctiva. However, the donor cornea was completely attached to the recipient cornea. The implanted IOL was not dislocated and there were no abnormal findings in the posterior segment (Fig. 2). We performed emergency treatment of wound suturing and iris reconstruction (the second operation). We made a conjunctival incision and removed the prolapsed iris. After cutting off the aberrant vitreous in the anterior chamber, we sutured the ruptured wound. After the second operation, adhesion of the transplanted endothelium and Descemet's membrane was in good condition although Descemet's fold and inflammation in the anterior chamber were observed. At 45 months after the second operation, Descemet's fold and anterior chamber inflammation improved and the recipient and donor cornea retained clarity (Fig. 3). His visual acuity was $20 / 25$ and endothelial cell count was maintained at 1,049 cells $/ \mathrm{mm}^{2}$.

\section{Discussion}

We encountered a case of traumatic globe rupture five years after nDSAEK with scleral suture fixation of IOL. Traumatic globe rupture occurs in 0.6 to $5.8 \%$ of patients who underwent keratoplasty previously [ 1 , 2]. However, there are few reports on trauma after DSAEK. To our knowledge, this is the first report of traumatic globe rupture after DSAEK.

Our patient with traumatic wound dehiscence after nDSAEK had good visual outcome. During the course of injury in this case, the recipient and donor cornea was never detached from each other, and retained clarity. There was little difference between pre- and postoperative visual acuity in this patient. There are three possible reasons for the good clinical course after nDSAEK in our case. First, the wound of DSAEK is a partial incision, whereas the wound of PKP is a circumference incision. The partial incision of DSAEK maintains structural stability against external force. A previous report described a case of blowout fracture after DSAEK, but wound dehiscence did not occur nevertheless [10]. Second, it is possible that scleral suture fixation of IOL minimizes prolapse of the vitreous. To our knowledge, few studies have 
reported globe rupture after scleral suture fixation of IOL. Third, the corneoscleral incision also may have prevented vitreous prolapse. It is well known that corneoscleral incision is stronger compared with corneal incision. In this case, the iris prolapse was limited to beneath the conjunctiva, and did not extend to the extraocular region. For these reasons, we estimate that structural stability of DSAEK eye is much stronger than that of PKP eye.

In the present case, the incision for nDSAEK with scleral suture fixation of (IOL) was $7.5 \mathrm{~mm}$ in order to insert a 7-mm polymethyl methacrylate IOL, although the incision of DSAEK is normally within $5 \mathrm{~mm}$ [8]. In addition, the incision was made in the superior region. Previous report has shown that fixation of the globe to orbital bone is less supported inferiorly and the impact of blunt trauma at the inferior side is transmitted to opposite side of the cornea, suggesting that superior wound tends to dehisce more frequently than wounds at the other sides of the cornea [11]. Therefore we speculate that the wide superior wound probably led to traumatic globe rupture in our case.

\section{Conclusion}

In conclusion, we encountered a case of traumatic globe rupture after nDSAEK. It can be presumed that traumatic wound dehiscence after DSAEK has better visual outcome than traumatic wound dehiscence after other PKP. DSAEK may be resistant to traumatic injury because of the minimal incision compared with PKP.

\section{Abbreviations}

DSAEK = Descemet's stripping automated endothelial keratoplasty; nDSAEK = non-Descemet's stripping automated endothelial keratoplasty; PKP = penetrating keratoplasty; DALK = Deep anterior lamellar keratoplasty; IOL = intraocular lens; IOP = intraocular pressure; $A S-O C T$ = anterior segment optical coherence tomography

\section{Declarations}

\section{Ethics approval and consent to participate}

This study was approved by the Tokyo medical University Ethics Committee and adhered to the tenets of the Declaration of Helsinki.

\section{Consent for publication}

Written informed consent was obtained from the patient for publication of this case report and any accompanying images.

\section{Availability of data and material}

All data are shown in the figures. 


\section{Competing interests}

The authors declare that they have no competing interests.

\section{Funding}

None.

\section{Authors' contributions}

AN carried out substantial parts of the work including diagnosing the patient, drafting the manuscript, and finalizing it. TH participated in the treatment of the patient and helped finalize the manuscript. HK and TM participated in treatment of the patient. SK participated in treatment by performing nDSAEK, IOL fixation, wound suturation and the iris reconstruction, and following up the patient. HG helped finalize the manuscript and gave the final approval of the version to be published. All the authors have read and approved the final manuscript.

\section{Acknowledgements}

None.

\section{References}

1. Kawashima M, Kawakita T, Shimmura S, Tsubota K, Shimazaki J. Characteristics of traumatic globe rupture after keratoplasty. Ophthalmology 2009; 116: 2072-6.

2. Elder MJ, Stack RR: Globe rupture following penetrating keratoplasty. how often, why, and what can we do to prevent it?. Cornea 2004; $23: 776-80$.

3. Tseng SH, Lin SC, Chen FK: Traumatic wound dehiscence after penetrating keratoplasty. clinical features and outcome in 21 cases. Cornea 1999; 18:553-8.

4. Steinberg J, Eddy MT, Katz T, Fricke OH, Richard G, Linke SJ. Traumatic wound dehiscence after penetrating keratoplasty: case series and literature review. European Journal of Ophthalmology 2012; 22:335-41.

5. Renucci AM, Marangon FB, Culbertson WW. Wound dehiscence after penetrating keratoplasty: clinical characteristics of 51 cases treated at Bascom Palmer Eye Institute. Cornea 2006; 25:524-9.

6. Prasher P, Muftuoglu O, Mootha VV. Traumatic graft dehiscence after anterior lamellar keratoplasty. Cornea 2009; 28:240-2.

7. Zarei-Ghanavati S, Zarei-Ghanavati M, Sheibani S. Traumatic wound dehiscence after deep anterior lamellar keratoplasty: protective role of intact descemet membrane after big bubble technique. Cornea 2010;29: 220-1.

8. Gorovoy MS: Descemet's stripping automated endothelial keratoplasty. Cornea 2006; 25:886-9. 
9. Price FW Jr, Price MO. Descemet's stripping with endothelial keratoplasty in 200 eyes: early challenges and techniques to enhance donor adherence. J Cataract Refract Surg 2006; 32:411-8.

10. 10 Tachibana E, Koh S, Maeda N, Nishida K. Blow out Fracture after Descemet's Stripping Automated Endothelial Keratoplasty. Case Rep Ophthalmol 2014;5: 357-60.

11. Foroutan AR, Gheibi GH, Joshaghani M, Ahadian A, Forountan P. Traumatic wound dehiscence and lens extrusion after penetrating keratoplasty. Cornea 2009; 28:1097-9.

\section{Figures}

(A)

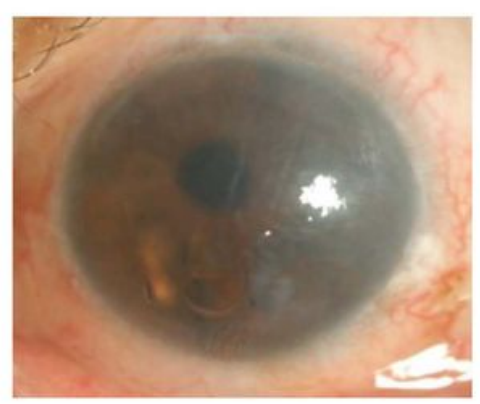

(B)

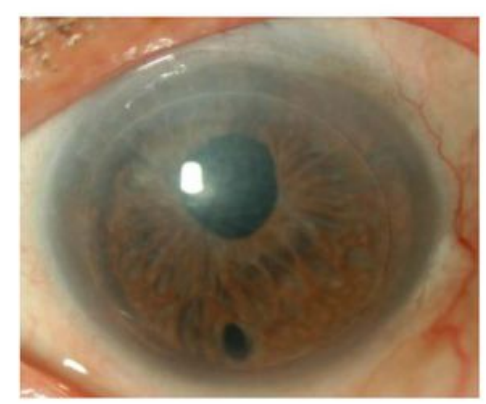

(C)

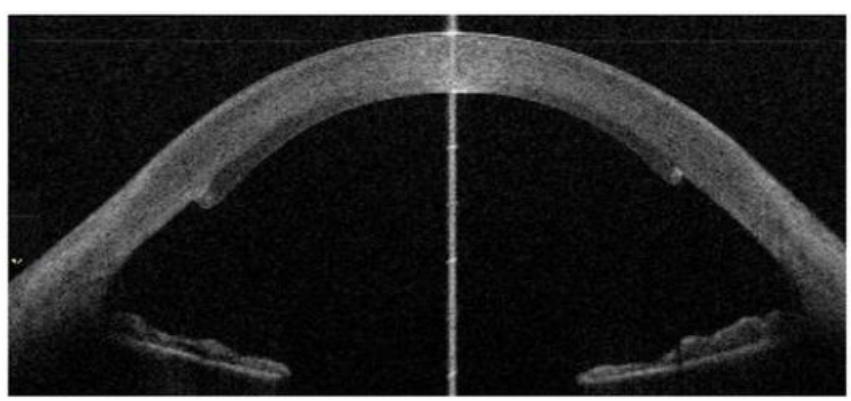

Fig. 1

\section{Figure 1}

Pre- and postoperative slit-lamp examination and anterior-segment optical coherence tomography (ASOCT) of the left eye. Slit-lamp examination before surgery shows bullous keratopathy (A). Slit-lamp examination after nDSAEK shows improvement of the bullous keratopathy (B). AS-OCT shows good attachment of the donor cornea graft (C). 
(A)

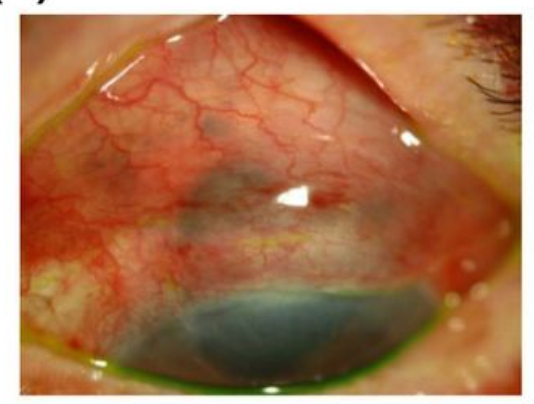

(B)

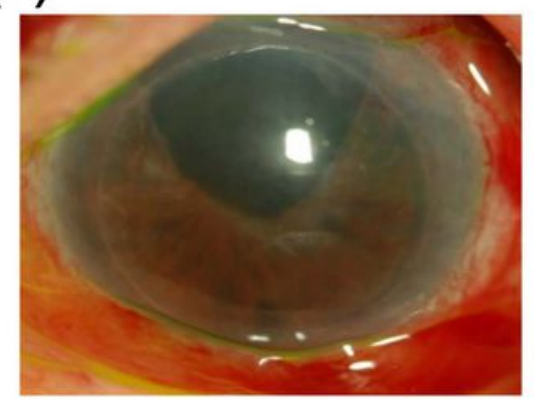

Fig. 2

Figure 2

Slit-lamp examination of the globe rupture. The operative wound is open and the iris prolapses beneath the conjunctiva (A). After surgery, cornea and intraocular lens are intact (B). 
(A)

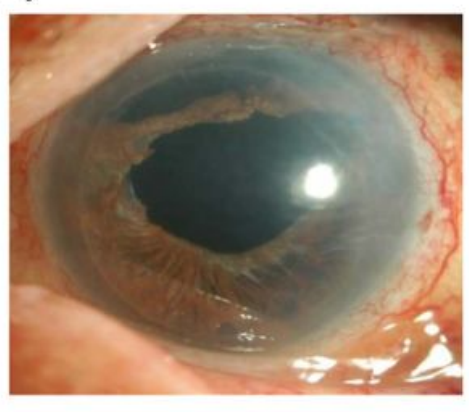

(B)

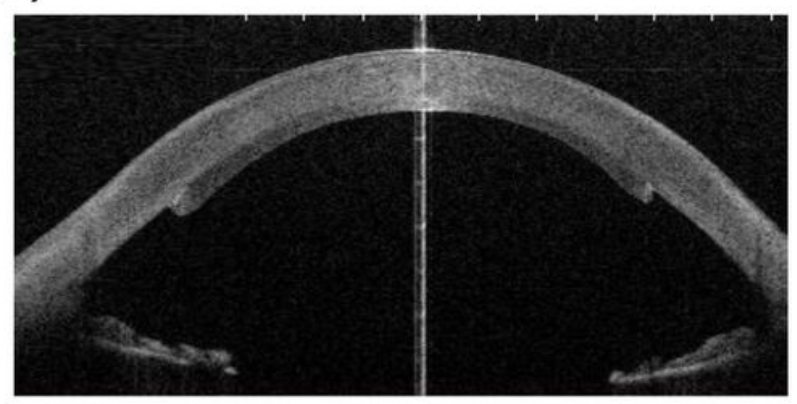

Fig. 3

\section{Figure 3}

Slit-lamp examination and anterior-segment optical coherence tomography (AS-OCT) after wound suturation and iris reconstruction. The cornea remains clear with vision 20/25 (A). Adhesion of donor cornea is good (B).

\section{Supplementary Files}

This is a list of supplementary files associated with this preprint. Click to download.

- supplement1.pdf 